dissertations on classification technique. However, it is in terms of the depth and maturity of its deeper function-as a collective focus and appeal for research-that the Dorking Conference will either prove viable or wanting in the years ahead.

As a crystallizing medium for needed research, the Dorking Conference may prove limited to a certain extent by its inferential definition of research. To be sure, if all of the successive recommendations were fulfilled, applied knowledge and technological know-how in classification and information retrieval would unquestionably be enriched. Research, for example, is called for in the area of analysis (facet, relational, codifying, semantic, synthetic, and linguistic). Research is also proposed in the development of classification schedules, and in the designing of a universal scheme. Upon review, these recommendations, given great weight and detail at Dorking, would appear to gravitate more about classification engineering than classification research, and to lend themselves more to mechanical and technological in- ventiveness than to the objective methods of academic research.

Much less emphasis is placed upon logically researchable areas such as quantitative and qualitative usage studies, and comparative analysis of internal characteristics of information systems, such as relative efficiency or cost. These vital areas, awaiting fuller research, are defined in the Dorking recommendations but with detectably lowered enthusiasm and reduced detail. It is interesting, for example, to compare the maturity and foresight which accompanies their description at Dorking, with the research prospectus of the Washington International Conference on Scientific Information, 1958, which de-emphasizes application and technique in order to isolate, in a highly detailed manner, those areas lending themselves to a variety of objective research methods. It is quite possible that the ideas expressed at the Washington Conference may have some influence in accelerating research in areas of classification and information retrieval.-Frederic D. Weinstein, New Haven State Teachers College.

\title{
Comment
}

\section{"Human Relations Training for Librarians? Yes, But-"}

The suggestion that library schools offer courses in interpersonal relations, as set out in the article, "Human Relations Training for Librarians?" (CRL, XIX (1958), 227-29) at first found this reader in agreement.

Then he found himself resisting the proposal. Or at least doubting its efficacy.

The proposition-that there is a definite need for librarians to study and understand the dynamics of human behavior-is beyond dispute. That point was well made by Mr. Anderson and Dr. Kell. It is true that library work is a service occupation-profession: essentially, we help others carry out their purposes in pursuing the use of library materials (and in so doing seek our own fulfillment). And it follows that we ought to work hard at comprehending the wondrous workings of the human mind and the complex of emotional responses which combine to produce motivation, attitudes, action, and reaction.

Still, the writer wonders about the proposal that courses adapted specifically to human behavior in the library field be taught in library schools, or as part of library school curriculum. In fairness to authors Anderson and Kell he freely acknowledges that it is easier to render critiques of others' proposals than construct a recommendation of one's own. What follows is not intended as a rebuttal, but only a summation of the reasons for the doubt in his mind about the proposal.

The proper study of man (in the sense under discussion) would seem to rest with the behavioral or social science faculty offering basic undergraduate instruction in sociology, psychology, philosophy, cultural anthropology (and perhaps a graduate course in human dynamics).

Few persons probably would disagree with 
the point just made, but many librarians might reasonably ask, "What of the library school student who has had little or no background in the social sciences? Would not a library course or two in human relations at least help bridge this gap?"

This writer's answer would be a qualified yes, if said student were allowed or required to take a basic course(s) in the social science discipline, taught by the social science faculty.

Authors Anderson and Kell suggest that library schools emulate the medical, legal, and nursing professions in giving special instruction on concrete human relations situations in the field. Why not join hands with all service occupations and professions on campus and together request a good, solid course in human dynamics applicable to all interested groups-lawyers, librarians, journalists, or whatever?

It would seem a waste of faculty for each group to undertake this on its own. Human relations as applied specifically to librarians, to lawyers, doctors, and other such groups would seem a rather desperate attempt to give the students some background, that he has not acquired along the way.

But why should any subject field adapt for itself, at the college level, fundamental theories which, once learned, can apply in all situations-in libraries as well as in oil fields? Human relations is nothing more than the study of human behavior; there is nothing on record which would indicate that librarians as a group, and the people with whom they come into contact, are sufficiently aberrant to warrant special attention.

An applied course in human behavior, dealing with interpersonal relations in library work, smacks too much to this writer of a Dale Carnegie, or power of positive circulation approach. Possibly it need not be so, but the situation does not in itself augur well for the best results. What we are really after is not the acquisition of skill in manipulating people but the recognition of universal values and hungers that, conditioned by environment and culture, make us sometimes lovable, sometimes contrary, human beings who are to be cherished despite and perhaps because of our many weaknesses.

After all is said about the best way of imparting the import of interpersonal communication through force feeding, this much still remains: The techniques and principles of personnel psychology can be taught and theoretically learned, if we feel this is important enough for all library school students. But that rare quality of empathythe ability to put one's self in another's position-comes (if it comes at all) in response to one's own motivation. That motivation itself will be the sum total of personality, study, observation, and life experiences.Frank D. Hankins, Librarian, Del Mar College, Corpus Christi, Texas.

\section{Rare Books Conference}

Sufficient expressions of interest have been received to assure holding the Rare Books Conference planned by ACRL's Rare Books Section for Charlottesville, Virginia, June 18-20.

Reservation forms for the conference will be mailed in a few days to those who have already made tentative reservations. Others should request them from William H. Runge, Alderman Library, University of Virginia, Charlottesville, Virginia. Total registration will be limited, so early reservations are advisable. The registration fee of $\$ 30.00$ includes conference fees, a single room in a university dormitory for two nights, and six meals in the student union. A limited number of double rooms for married couples will be available at the same fee per person. The entrance fee for registrants wishing to make their own living arrangements will be $\$ 25.00$, with meal tickets available at additional cost. 